\title{
A HISTÓRIA DA CARTOGRAFIA NO CENTRO DE ESTUDOS GEOGRÁFICOS DE LISBOA, 2000-2010
}

\author{
MARIA FERNANDA ALEGRIA ${ }^{1}$
}

\begin{abstract}
Resumo - Uma boa parte das publicações do núcleo de História e Ensino da Geografia e da Cartografia (HEGEC), um dos núcleos de investigação do Centro de Estudos Geográficos (CEG, ) centra-se na História da Cartografia, tema de investigação iniciado entre os geógrafos portugueses por Suzanne Daveau. Esta síntese bibliográfica dá conta das cerca de 100 publicações dos investigadores desse núcleo entre 2000 e 2010, considerando 6 grupos temáticos: 1. Estudos cartográficos de síntese; 2. Cartografia terrestre; 3. Cartografia náutica; 4. Cartógrafos e instituições cartográficas; 5. Contributos teóricos e metodológicos; 6. Colecções de mapas e atlas. Os textos inventariados com base nesta classificação por assunto, são também objecto de análise por autor, ano, local e língua de edição. O número e a variedade de estudos temáticos e regionais mostram que a História da Cartografia portuguesa tem tido lugar de relevo entre os geógrafos.
\end{abstract}

Palavras-chave: História da cartografia, inventário, classificação temática.

\begin{abstract}
THE HISTORY OF CARTOGRAPHY AT THE CENTRO DE Estudos GEOGRÁFICOS DE LISBOA, 2000-2010. A large number of the publications in History and Teaching of Geography and Cartography (HEGEC), a research unit of the Centre for Geographical Studies (CEG), focus on the history of cartography. Suzanne Daveau first suggested this research theme to the Portuguese geographers. The current bibliographical synthesis gives an account of approximately 100 publications by the researchers of this nucleus, between 2000 and 2010, and covers six thematic groups: 1. Synthesis Cartographic studies; 2. Terrestrial cartography; 3. Nautical cartography; 4. Cartographers and cartographic institutions; 5. Theoretical and methodological contributions; 6 . Collections of maps and atlases. Although the inventory classified the texts according to subject, they are also analysed by author, year, location and language of publication. The number and variety of regional and thematic studies show that the history of Portuguese Cartography has taken a place of prominence amongst geographers.
\end{abstract}

Keywords: History of cartography, inventory, thematic classification.

Recebido: Janeiro 2011. Aceite: Setembro 2011.

1 Investigadora do Centro de Estudos Geográficos da Universidade de Lisboa. E-mail: mfalegria (a)netcabo.pt 
Résumé - L'Histoire DE LA CARTOGRAPHIE AU SEIN DU CENTRE D’ÉTUDES GÉOGRAPHIQUES DE LISBONNE, 2000-2010. Une bonne partie des publications de l'unité de recherche Histoire et Enseignement de la Géographie et de la Cartographie (HEGEC), qui est l'une des unités de recherche du Centre d'Études Géographiques (CEG), porte sur l'Histoire de la Cartographie, thème d'investigation entrepris au sein des géographes portugais par Suzanne Daveau. Cette synthèse bibliographique rend compte de près de 100 publications que les chercheurs de cette unité ont fait paraître entre 2000 et 2010, considérant les 6 groupes thématiques suivants: 1 . Études cartographiques de synthèse; 2 . Cartographie terrestre; 3. Cartographie nautique; 4. Cartographes et institutions cartographiques; 5. Contributions théoriques et méthodologiques; 6 . Recueils de cartes et atlas. Les textes inventoriés sur la base de cette classification thématique sont également analisés par auteur, par année, par lieu et par langue d'édition. Le nombre et la variété des études thématiques et régionales montrent que l'Histoire de la Cartographie portugaise a occupé une place importante chez les géographes.

Mots-clés: Histoire de la Cartographie, inventaire, classification thématique.

Poucos saberão que o interesse pela Cartografia e a sua História teve início entre os geógrafos portugueses no ano lectivo de 1976/77, quando a Professora Suzanne Daveau orientou no Centro de Estudos Geográficos da Universidade de Lisboa (CEG) um seminário livre sobre Expressão Gráfica em Geografia. Parte dos actuais investigadores em História da Cartografia foram então seus alunos e souberam aproveitar o estímulo que receberam, em particular Maria Helena Dias e Maria Fernanda Alegria. Estas duas investigadoras e João Carlos Garcia, do CEG, viriam a integrar, com Suzanne Daveau, o grupo de História e Ensino da Geografia e da Cartografia (HEGEC), criado formalmente apenas em 2009. João Carlos Garcia, o coordenador até ao início de 2011, incorporaria aí três dos seus discípulos: André Ferrand de Almeida, Luís Miguel Moreira e Jorge Macieirinha Ribeiro. O grupo integra ainda Francisco Roque Oliveira, um investigador em Geografia Humana e Cultural, com trabalhos recentes sobre a Cartografia e a sua História.

$\mathrm{O}$ reconhecido trabalho dos pioneiros da História da Cartografia portuguesa $-2^{\circ}$ Visconde de Santarém, Jaime Cortesão e Armando Cortesão, Avelino Teixeira da Mota e Luís de Albuquerque -, para citar apenas os mais ilustres e, simultaneamente, os mais próximos de nós no tempo, têm tido, assim, o seu trabalho continuado.

\section{CRITÉRIOS E CLASSIFICAÇÃO DAS PUBLICAÇÕES}

Para elaborar a lista de textos que se apresenta houve que definir alguns critérios de selecção, uma vez que era impensável incluir todas as publicações em História da Cartografia. Eis os principais.

Consideraram-se apenas as publicações entre 2000 e 2010, sendo excluídos os textos no prelo, ou policopiados. Esta opção impediu a menção a alguns títulos importantes, de que são exemplos, para anos anteriores, o livro coordenado por Maria Helena Dias Os Mapas em Portugal, 1995, e para anos posteriores, a História da Cartografia Portuguesa dos Séculos $X V$ a XVII, a editar no Porto, pela Fio da Palavra. O ano de 2000 não tem significado particular. Só se incluíram textos de autores que não pertencem ao CEG e ao HEGEC, se a obra em que participaram foi publicada em colaboração com um dos autores do CEG. 
Cada obra está referida apenas uma vez, ainda que conte com a participação de vários autores e que o mesmo assunto tenha sido objecto de edições diferentes, com pequenas diferenças no conteúdo. No caso de um dado investigador incluir um estudo numa colectânea, coordenada por ele próprio ou por um dos oito autores mencionados nesta recensão, esse título não é especificado separadamente: cita-se apenas a publicação no seu conjunto. A apresentação das obras é feita por ordem alfabética e em sequência cronológica. As fontes de informação foram o sítio do CEG na Internet (www.ceg.ul.pt) e, sempre que possível, a consulta das próprias obras. Os investigadores do HEGEC, puderam dar sugestões sobre a arrumação dos textos e indicar os que não estavam disponíveis na página do CEG

Atendendo ao grande número de publicações a organização dos textos em categorias era indispensável. Essa divisão foi, no entanto, complexa, tanto pela escolha do número de divisões temáticas como pela própria concepção dos grupos temáticos. É claro que, nalguns casos, houve indecisões quanto à inclusão de uma obra num dado grupo, já que algumas publicações têm características que permitiriam inclui-las em mais do que uma categoria. Acreditamos, todavia, que esses casos não invalidam o conjunto dos seis conjuntos temáticos considerados: 1. Estudos cartográficos de síntese; 2. Cartografia terrestre; 3. Cartografia náutica; 4. Cartógrafos e instituições cartográficas; 5 . Contributos teóricos e metodológicos; 6. Colecções de mapas e atlas. Eis sumariamente as características de cada categoria.

A consideração do grupo 1. Estudos cartográficos de síntese, tem muito a ver com a dificuldade em incluir certas obras em duas das categorias que se podem considerar clássicas: a Cartografia náutica e a terrestre. Mas há que reconhecer que pode haver dúvidas na consideração deste grupo, atendendo ao reduzido número de obras aí incluído. O extenso grupo 2. Cartografia terrestre, pode ser questionado pela inserção nesse grupo de um ou outro texto que, eventualmente, estaria melhor noutro. A Cartografia náutica é uma designação tradicional, mas que abarca publicações de índole muito diversa: portulanos, mapas-mundo, cartas hidrográficas e mapas de regiões costeiras. O grupo 4. Cartógrafos e instituições cartográficas, não levanta problemas particulares, embora alguns textos pudessem ter sido inseridos na Cartografia terrestre. O grupo 5. Contributos teóricos e metodológicos, inclui textos de índole muito diversificada: conceitos, métodos de leitura e análise de mapas, reflexões teóricas e projectos de investigação. Finalmente, pareceu indispensável o grupo 6. Colecções de mapas e atlas, atendendo às inúmeras exposições de mapas que têm sido realizadas e aos catálogos sobre elas preparados.

A propósito da inclusão de alguns textos numa dada categoria temática, um dos grandes problemas das classificações temáticas referem-se, a título de exemplo, alguns casos duvidosos. O estudo de Maria Helena Dias e José Manuel dos Ramos Rossa - Dos Serviços Cartográficos ao Instituto Geográfico do Exército: 75 anos de actividade a servir Portugal, 1932-2007 -, foi incluído no grupo dos estudos de síntese embora, como se depreende pelo título, ele pudesse figurar na categoria "Cartógrafos e instituições cartográficas", porque nele se faz uma resenha sobre a institucionalização da Cartografia portuguesa até ao início do século XXI, com referência a aspectos gerais da evolução desta ciência. Outro exemplo é a publicação de Maria Helena Dias sobre os mapas da fronteira terrestre portuguesa - Finis Portugalliae: nos confins de Portugal: cartografia militar e identidade territorial -, que foi incluído na "Cartografia terrestre" mas que poderia ter ficado na categoria "Colecções de mapas e atlas".

Registe-se, finalmente, que não se consideraram categorias cartográficas regionais Portugal, Brasil, Angola, ou outros espaços -, embora no comentário que se segue se façam menções a estudos sobre essas áreas. 


\section{COMENTÁRIO}

Como se compreenderá, não se vai fazer uma apreciação de cada um dos títulos que integram a lista de publicações, mas apenas breves considerações gerais.

Este elevado número de textos tem representação desigual nas diversas categorias temáticas. Ordenando-as por valores crescentes temos a sequência indicada no quadro I.

Quadro I - Número de publicações sobre História da Cartografia de investigadores do CEG, por categoria temática, 2000-2010.

Table I-Number of publications by CEG's researchers on the History of Cartography, according to category topic, 2000-2010.

\begin{tabular}{lc}
\hline \multicolumn{1}{c}{ Categorias temáticas } & N. $^{\mathbf{0}}$ de publicações \\
\hline Estudos cartográficos de síntese & 7 \\
Cartografia náutica & 9 \\
Cartógrafos e instituições cartográficas & 10 \\
Colecções de mapas e atlas & 17 \\
Contributos teóricos e metodológicos & 20 \\
Cartografia terrestre & 37 \\
\hline Total & $\mathbf{1 0 0}$ \\
\hline
\end{tabular}

As 100 publicações indicadas são por defeito, uma vez que se um autor é coordenador de uma dada colectânea, os seus textos aí inseridos não foram citados. Além disso, em obras de tipo dicionário, ou colectânea de textos curtos, cada autor só é mencionado uma vez em cada ano, ainda que tenha contribuído com várias entradas nesse ano.

Nos 6 estudos cartográficos de síntese, dos quais 5 foram publicados depois de 2006, há obras sobre o conjunto da Cartografia portuguesa e também sobre a Cartografia europeia e a brasileira, com participação de seis dos oito autores aqui considerados.

Foi João Carlos Garcia quem mais publicou na categoria Cartografia náutica, tanto sobre mapas-mundo como sobre o Brasil. Mas o histórico grupo "Cartografia náutica" tem perdido nitidamente terreno face à Cartografia terrestre e a outras divisões temáticas o que é um sinal nítido de renovação da investigação.

Os títulos sobre cartógrafos e instituições cartográficas mereceram ampla divulgação através do Instituto Camões, numa publicação coordenada pelo Professor Nuno Crato em que Maria Helena Dias tem várias entradas (Charles Bonnet, J. M. Neves Costa, Francisco António Ciera, B. Barros Gomes). João Carlos Garcia publicou também quatro estudos sobre os cartógrafos Armando Cortesão, Manoel Azevedo Fortes e o 2. ${ }^{\circ}$ Visconde de Santarém. Os investigadores Francisco Roque Oliveira e André Ferrand de Almeida têm estudos, respectivamente, sobre Jaime Cortesão e Samuel Fritz.

$\mathrm{Na}$ categoria colecções de mapas e atlas a maior parte dos textos deve-se a João Carlos Garcia, com inúmeros títulos, individuais ou em colaboração, sobre África, o Brasil ou Portugal, incluindo inventários sobre colecções públicas e privadas. A recolha e divulgação de colecções de mapas são indispensáveis para a elaboração de estudos sobre a História da Cartografia, que ele próprio e os seus colaboradores têm realizado.

O grupo das contribuições teóricas e metodológicas é porventura o mais diversificado, já que nele participam sete autores, com uma grande variedade de estudos. Os títulos dos textos falam por si no que toca à multiplicidade de investigações. 
A Cartografia terrestre tem merecido uma atenção particular nos últimos anos. Neste conjunto temático há diversos textos de Suzanne Daveau, sobre os mapas corográficos e a representação dos rios portugueses nos mapas antigos. A mesma investigadora publicou em finais de 2010 um livro notável sobre um desconhecido mapa de Portugal de c. 1525, que vai ser seguramente objecto de próximas recensões. Tem sido, porém, Maria Helena Dias a mais prolífica neste campo. As suas sólidas investigações sobre o nascimento da moderna Cartografia, um período de transição muito rico e desconhecido, levaram à edição de vários textos, excelentemente ilustrados, sobretudo desde o início da sua colaboração com o Instituto Geográfico do Exército. Essas publicações, que incidem sobre os começos da moderna Cartografia, incluem estudos sobre antigas formas de representação do relevo, os rios e a figuração da fronteira terrestre, para citar os temas mais trabalhados. Na categoria Cartografia terrestre João Carlos Garcia publicou também títulos sobre temas diversificados: os mapas e as invasões francesas, a fronteira terrestre, o Alentejo, a Cartografia vinhateira do Douro, etc. É neste grupo que se incluem os trabalhos sobre África, de Jorge Macieirinha Ribeiro, e de Luís Miguel Moreira, o mais jovem membro do grupo, sobre o Minho.

Tentando agora uma categorização regional do conjunto da lista de publicações há que destacar além de Portugal, nitidamente dominante, os 15 estudos cartográficos sobre o Brasil (em boa parte devidos a João Carlos Garcia e a André Ferrand de Almeida, com contributos de Francisco Roque Oliveira e de Maria Fernanda Alegria), vários textos sobre Angola e Cabo Verde (de João Carlos Garcia e discípulos), 3 textos sobre a China, e particularmente Macau (Francisco Roque Oliveira), e um sobre o litoral africano (Suzanne Daveau).

Neste grupo de investigadores o número de publicações de cada um é diferente, entre outros motivos porque alguns dispersam a sua actividade por vários campos, e também porque há grandes diferenças na dimensão dos textos: notas, artigos mais ou menos longos, livros (quadro II).

Quadro II - Número de publicações sobre História da Cartografia de cada um dos investigadores do CEG, 2000-2010.

Table II - Number of publications by each of CEG's researchers on the History of Cartography, 2000-2010.

\begin{tabular}{lc}
\hline \multicolumn{1}{c}{ Investigadores } & Número de publicações \\
\hline Jorge M. Ribeiro & 3 \\
M. Fernanda Alegria & 6 \\
Suzanne Daveau & 6 \\
Luís M. Moreira & 8 \\
Francisco R. Oliveira & 13 \\
André F. de Almeida & 16 \\
M. Helena Dias & 24 \\
João C. Garcia & 38 \\
\hline Total & $\mathbf{1 1 4}$ \\
\hline
\end{tabular}

Como se vê, o número de publicações é superior ao total do quadro 1, porque algumas delas são da responsabilidade de mais do que um investigador e há textos publicados por mais do que uma pessoa..

Quanto ao número de publicações em cada ano (quadro III), não há regularidade: no conjunto dos 11 anos a média é de cerca de 9 textos por ano, mas nos últimos 5 anos atingiram-se os 12. Esperemos que médias desta ordem se continuem a registar em anos vindouros. 
Quadro III - Número de publicações sobre História da Cartografia de investigadores do CEG em cada ano, $2000-2010$.

Table III - Number of publications by CEG's researchers during each calendar year, 2000-2010, on the History of Cartography.

\begin{tabular}{|c|c|}
\hline Ano & N. ${ }^{0}$ de publicações \\
\hline 2000 & 10 \\
\hline 2001 & 9 \\
\hline 2002 & 3 \\
\hline 2003 & 11 \\
\hline 2004 & 1 \\
\hline 2005 & 5 \\
\hline 2006 & 16 \\
\hline 2007 & 13 \\
\hline 2008 & 9 \\
\hline 2009 & 12 \\
\hline 2010 & 11 \\
\hline Total & 100 \\
\hline Média dos 11 anos & 9,1 \\
\hline
\end{tabular}

A diversidade de locais de edição é enorme (quadro 4). Em Portugal, o maior número de edições tem lugar na cidade de Lisboa (55), seguida do Porto (10), de Coimbra (8) e de Viana do Castelo (2). Há mais 5 cidades com uma edição em cada: Aveiro, Melgaço, Peso da Régua e Ponta Delgada. Em Espanha as cidades são: Zamora, Valência, Santander e Madrid, além de Barcelona, que figura em edição conjunta com a Cidade do México e com S. Paulo. Em Itália os locais de edição foram Florença (4) e Palermo (1). No Brasil: São Paulo (5) e Fortaleza (1). Nos Estados Unidos: Washington (2) e Chicago (1). No México, a Cidade do México (2).

Quadro IV - Locais de edição das publicações sobre História da Cartografia de investigadores do CEG, $2000-2010$.

Table IV-Places of issue of publications by CEG's researchers on the History of Cartography, 2000-2010.

\begin{tabular}{|c|c|c|c|}
\hline Locais de edição & N. ${ }^{\circ}$ de títulos editados & Locais de edição & N..$^{0}$ de títulos editados \\
\hline Europa & 83 & América & 12 \\
\hline Portugal & 68 & Brasil & 6 \\
\hline Espanha & 4 & Estados Unidos & 3 \\
\hline Itália & 5 & México & 2 \\
\hline Reino Unido & 2 & Argentina & 1 \\
\hline França & 1 & & \\
\hline Hungria & 1 & Ásia (Macau) & 1 \\
\hline Mista (Port. e Esp.) & 2 & Sem local & 1 \\
\hline Cabo Verde (Praia) & 3 & & \\
\hline Total geral & & & 100 \\
\hline
\end{tabular}

É pena que a diversidade de locais não tenha correspondência na diversidade linguística, pois quase todos os textos foram editados em português (75). São excepções apenas 25 
publicações: 8 em inglês, 6 em espanhol, 6 em edição bilingue (português e espanhol ou português e inglês), 3 em italiano, 1 em francês e 1 em romeno.

Outra característica a alterar diz respeito à disponibilidade dos textos na Internet. Se uma parte já pode ser aí consultada, nem todos foram disponibilizados. Essa situação dever-se-á a decisão do próprio editor, nalguns casos, mas noutros a omissão talvez possa ser remediada.

O grande número e a variedade de estudos temáticos e regionais mostra bem, todavia, quão viva tem estado a História da Cartografia portuguesa entre os geógrafos. Esperemos que assim continue.

\section{LISTA DE PUBLICAÇÕES}

\section{Estudos Cartográficos de Síntese}

Alegria M F, Daveau S, Garcia J C, Relaño F (2007) Portuguese Cartography in the Renaissance. In Woodward D (ed.) - The history of cartography. University of Chicago Press, Chicago, III(I): 975-1068.

Almeida A F, Curto D R, Cattaneo A (coord.) (2003) La cartografia europea tra primo Rinascimento e fine dell'Illuminismo. Leo S. Olschki Editore, Florença. (Accademia Toscana di Scienze e Lettere 'La Colombaria', studi CCXIII).

Almeida A F (2001) A formação do espaço brasileiro e o projecto do novo atlas da América Portuguesa, 1713-1748. Comissão Nacional para as Comemorações dos Descobrimentos Portugueses, Lisboa.

Amorim I, Garcia J C (coord.) (2010) La Barra y los Puertos de la Ria de Aveiro, 1808-1932. Archivo de la Administración del Puerto de Aveiro. Administração do Porto de Aveiro, Aveiro.

Dias M H (2006) - Portugalliae descriptio: do primeiro mapa conhecido (1561) ao primeiro mapa moderno (1865). Instituto Geográfico do Exército, Lisboa.

Disponível em: http://www.fl.ul.pt/mapoteca/ catalogo.pdf (em português); www.fl.ul.pt/ mapoteca/Brochura igeo_Bilingue.pdf (em inglês e francês); www.igeoe.pt/portugalliae descriptio/descriptio.htm (exposição)

Dias M H, Rossa J M R (2007) Dos Serviços Cartográficos ao Instituto Geográfico do Exército: 75 anos de actividade a servir Portugal, 1932-2007. Instituto Geográfico do Exército, Lisboa. Disponível em: http://www.igeoe.pt/ instituto/75anos_IGeoE.pdf
Oliveira F R, Mendoza Vargas H (coord.) (2010) Mapas de metade do Mundo. A cartografía e a construção territorial dos espaços americanos. Mapas de la mitad del Mundo. La cartografía y la construcción territorial de los espacios americanos. Centro de Estudos Geográficos. Universidade de Lisboa, Lisboa. Instituto de Geografía. Universidad Nacional Autónoma de México, Ciudad de México.

\section{Cartografia Terrestre}

Alegria M F, Garcia J C (2002) A cartografia hidrográfica de Portugal Continental na segunda metade do século XIX e início do século XX. In O litoral em perspectiva histórica. Séculos XVII e XVIII. Actas Faculdade de Letras da Universidade do Porto, Porto: 9-20.

Almeida A F (2009) O mapa geográfico de América Meridional de Juan de la Cruz Cano y Olmedilla. Anais do Museu Paulista. Museu Paulista da Universidade de S. Paulo, São Paulo: 17(2): 79-89. Disponível em: http:// www.scielo.br/scielo.php?script=sci_arttext \&pid $=$ S0101-47142009000200003\&lng=pt \&nrm=iso\&tlng=pt.

Almeida A F (2009) A viagem de José Gonçalves da Fonseca e a Cartografia do Rio Madeira (1749-1752). Anais do Museu Paulista. Museu Paulista da Universidade de S. Paulo, São Paulo: 17(2): 215-235. Disponível em: http:// www.scielo.br/scielo.ph?script $=$ sci arttext\&pid=S0101-47142009000200006\&ln $\mathrm{g}=\mathrm{pt} \& \mathrm{nrm}=$ iso

Almeida A F (2006) "Arrumar as terras, os rios e os montes". Os jesuítas matemáticos e os mapas do Brasil meridional (1720-1748). In Fernan- 
des M G (coord.) Manoel de Azevedo Fortes (1660-1749). Cartografia, Cultura e Urbanismo. Gabinete de Estudos de Desenvolvimento e Ordenamento do Território (GEDES), Departamento de Geografia da Faculdade de Letras da Universidade do Porto, Porto: $99-122$.

Almeida A F (2000) Os jesuítas matemáticos e os mapas da américa portuguesa (1720-1748). Oceanos, 40, Lisboa: Comissão Nacional para as Comemorações dos Descobrimentos Portugueses, p.79-92.

Daveau S (2010) Um antigo mapa corográfico de Portugal (c. 1525). Reconstituição a partir do Códice de Hamburgo. Centro de Estudos Geográficos, Lisboa.

Daveau S (2007-2008) O fragmento de mapa corográfico de Portugal da Real Academia de la Historia de Madrid. Fases de realização e de utilização. Cadernos de Geografia, 26-27: 3-17.

Daveau S (2003) Conhecimento actual da representação corográfica de Portugal no século XVI. In Campar A, et al. (coord.) Olhar o Mundo, ler o território: uma viagem pelos mapas. Instituto de Estudos Geográficos, Coimbra: 33-37.

Daveau S (2000) A rede hidrográfica no mapa de Portugal de Fernando Álvaro Seco. Finisterra Revista Portuguesa de Geografia, XXXV(69): 11-38.

Dias M H (2008) Representações das formas do terreno nas cartas portuguesas. Boletim do Instituto Geográfico do Exército, 70: 4-12. Disponível em: http://www.fl.ul.pt/mapoteca/ boletim\%202008_mhdias.pdf

Dias M H (2006) A primeira carta de Portugal Continental [Em linha]; A carta geográfica de Portugal de 1865 [Em linha] In: Crato N (coord.) Ciência em Portugal: personagens e episódios. Instituto Camões, Lisboa. [Consult. 12 de Janeiro de 2011 e 14 de Janeiro de 2011]. Disponível em: http://www.instituto-camoes. $\mathrm{pt} / \mathrm{cvc} / \mathrm{ciencia} / \mathrm{e} 79 . \mathrm{html}$ e http://www.instituto-camoes.pt/cvc/ciencia/e76.html

Dias M H (2003) As explorações geográficas dos finais de Setecentos e a grande aventura da Carta Geral do Reino de Portugal. Revista da Faculdade de Letras, I série, XIX: 383-396. Disponível em: http://ler.letras.up.pt/uploads/ ficheiros/344.pdf
Dias M H (2001) A imagem do espaço nacional e o papel da Cartografia militar portuguesa. Revista Militar, 53(1): 27-57.

Dias M H, Instituto Geográfico do Exército (2010) Cursos e percursos para o mar oceano. Intervenções nos rios portugueses e representações de cartografia militar. Instituto Geográfico do Exército, Lisboa.

Dias M H, Instituto Geográfico do Exército (2009) Finis Portugalliae: nos confins de Portugal: cartografia militar e identidade territorial. Instituto Geográfico do Exército, Lisboa.

Dias M H, Instituto Geográfico do Exército (2008) Portugalliae Civitates: perspectivas cartográficas militares. Instituto Geográfico do Exército, Lisboa. Disponível em: http://www.fl. ul.pt/mapoteca/catalogo_civitates.pdf; http:// www.igeoe.pt/portugalliae_civitates/civitates/civitates.htm(exposição)

Dias M H, Rodrigues M L (2000/2001) Imagens de ontem e de hoje: a Beira Interior e a Cartografia militar portuguesa. Revista da Faculdade de Letras, 5. ${ }^{\mathrm{a}}$ série, 25: 131-145.

Garcia J C (2009) Os mapas da segunda invasão francesa. In Oliveira L V (coord.) O Porto e as Invasões Francesas, 1809-2009. Público, Câmara Municipal do Porto: 251-276.

Garcia J C (2009) Esta carta é da região do Grande Brasil: projectos cartográficos imperiais portugueses do século XVI. In Geraides De Lemos A I, Galvani E (coord.) Geografia, tradições e perspectivas: a presença de Pierre Monbeig. Clacso, Expressão Popular, Buenos Aires e São Paulo, I: 247-256.

Garcia J C (2009) Cartas Geographicas de Portugal (1860-1899). In Carolino L M, Mota T S (coord.) Medir os Céus para dominar a Terra. Museu de Ciência da Universidade de Lisboa, Lisboa: 17-21.

Garcia J C (2006) A 'Defensa da Província de Alentejo' nos mapas dos séculos XVII a XIX. In Mascarenhas Major - General António José Maia de (coord.) O Além Tejo fronteira. Exposição - Exército Português - Direcção de Infra-Estruturas, Lisboa: 6-11.

Garcia J C (2001) Nos contrafortes dos Andes: reflexões geográficas sobre a Cartografia do Brasil Setecentista. Actas das VI Jornadas de História Ibero-Americana. Portugal e o Brasil no advento do Mundo Moderno. Ed. Colibri, Lisboa: 91-100. 
Garcia J C (2000) A fronteira impressa: apontamentos sobre uma série cartográfica. In Trigal L L, Guichard F (coord.) La Frontera HispanoPortuguesa: nuevo espacio de atracción y cooperación. Fundación Rei Afonso Henriques, Zamora: 57-72.

Garcia J C, Branco D (2008) Forrester e a cartografia vinhateira do douro. In Cluny I (coord.) Barão de Forrester. Razão e sentimento. Uma história do douro, 1831-1861. Museu do Douro, Peso da Régua: 68-85.

Garcia J C, Moreira L M (2008) El geógrafo trabaja en su casa: espaços portugueses na produção cartográfica de Tomás López. Revista de Estudos Ibéricos, 5: 103-125.

Garcia J C, Ribeiro J M, Costa N S (2008) Representações do sal nos mapas do Arquivo da Administração do Porto de Aveiro. In Amorim I (coord.) A Articulação do Sal Português aos Circuitos Mundiais: antigos e novos consumos / The Articulation of Portuguese Salt with Worldwide Routes: past and new consumption trends. Instituto de História Moderna da Universidade do Porto, Porto: 265-271.

Garcia J C, Rodrigues V, Torrão M M (coord. 2010) Ilhas, Portos e Cidades. Cartografia de Cabo Verde (séculos XVIII-XX). Universidade de Cabo Verde e Instituto de Investigação Científica Tropical, Cidade da Praia / Lisboa.

Garcia J C, Santos M E M (2000) A representação antes da alienação: imagens cartográficas da organização do espaço angolano (c. 1883c.1930). In Santos M E M (coord.) A África e a Instalação do Sistema Colonial (c. 1885-c. 1930). Actas III Reunião Internacional de História de África. Lisboa: Centro de Estudos de História e Cartografia Antiga do Instituto de Investigação Científica Tropical: 91-115.

Moreira L M (2008) O sistema defensivo do Alto Minho em finais do século XVIII - O contributo do engenheiro militar Custódio José Gomes de Vilas Boas. Cadernos Vianenses, 41: $383-401$.

Moreira L M (2007) Um “coup d'oeil” sobre o Entre Douro e Minho pelo Engenheiro Militar Michel Lescolles, em 1661. Actas do II Simpósio Luso-Brasileiro da Cartografia Histórica. Instituto Geográfico Português, Lisboa: 20. Disponível em: http://www.igeo.pt/servicos/CDI/Parado/simposio/IISimposioLBCH files/LuisMiguelMoreira.pdf
Moreira L M (2006) A cartografia da província de Entre Douro e Minho nos finais do século XVIII. In Fernandes M G (coord.) Actas do Colóquio Manoel de Azevedo Fortes (16601749): Cartografia, Cultura e Urbanismo. GEDES - Departamento de Geografia da Faculdade de Letras da Universidade do Porto, Porto: $57-72$.

Moreira L M (2003) O Alto Minho nos finais do século XVIII: História das Populações e Cartografia Antiga. [CD-Rom] In Dias M H (coord.) Contributos para a História da Cartografia Militar Portuguesa - Projecto SIDCarta. Centro de Estudos Geográficos, Instituto Geográfico do Exército e Direcção dos Serviços de Engenharia, Lisboa.

Moreira L M, Garcia J C (2009) Castro Laboreiro na Guerra da Restauração: análise de duas plantas do castelo. Boletim Cultural de Melgaço, 8:75-92.

Oliveira F R (2009) Uma cidade, duas simbologias. Cartografia europeia e chinesa de Macau dos séculos XVI e XVII. In Mendoza Vargas H, Lois C (coord.) Historias de la Cartografia de Iberoamérica. Nuevos caminos, viejos problemas. Colección: Geografía para el siglo XXI. Serie: Libros de Investigación. México, D. F.: Instituto de Geografía, Universidad Nacional Autónoma de México; Aguascalientes, Ags.: Instituto Nacional de Estadística y Geografía de México, 4: 21-56.

Oliveira F R (2006) Cartografia antiga da cidade de Macau, c. 1600-1700: confronto entre modelos de representação europeus e chineses. Scripta Nova. Revista electrónica de geografia y ciencias sociales. Número extraordinario dedicado al VIII Coloquio Internacional de Geocrítica - Geografía histórica e historia del territorio. Actas del Coloquio. Ciudad de México, 22-26 de mayo 2006. Barcelona: Universidad de Barcelona, 1 de agosto de 2006, X(218) (53): 28 p. Disponível em: http://www.ub.es/geocrit/sn/sn-218-53.htm

Oliveira F R, Jin G P (2006) Mapas de Macau dos Séculos XVI e XVII. Inventário, Descrição e Análise Comparativa de Espécimes Cartográficos Europeus e Chineses. Revista de Cultu$r a$, International Edition, Macau: Instituto Cultural do Governo da R.A.E de Macau, 17, III ${ }^{a}$ Série/IIIrd Series Janeirop. 133-169.

Ribeiro J M (2006) O Sudoeste de Angola em 1929, segundo a Comissão de Cartografia: a elabo- 
ração de um mapa. In Santos M E, Lobato M (ccord.) $O$ domínio da distância. Instituto de Investigação Científica Tropical, Lisboa: 131-139.

\section{Cartografia Náutica}

Alegria M F, Dias M H (2000) Quatro séculos de imagens do litoral português: a região de Lisboa na Cartografia náutica nacional e estrangeira. Stvdia, 56-57: 61-96. Disponível em: http://www.fl.ul.pt/mapoteca/artigo STUDIA_ mhdias cores.pdf

Almeida A F (2009) Mapa da Costa do Brasil entre Pernambuco e o Rio da Prata. In J A Levenson, et al. (coord.) Encompassing the Globe. Portugal and the World in the 16th and 17th centuries. Reference Catalogue, Washington, D.C.: The Arthur M. Sackler Gallery, Smithsonian Institution, Washington, D.C., II: 187.

Daveau S (1999-2000) A propósito das 'pinturas' do litoral marroquino incluídas no Esmeraldo de Situ Orbis. Mare Liberum, 18-19: 79-132.

Garcia J C (2009) - Cantino. Planisfério, conhecido como 'de Cantino'. Portugal, c. 1502. In Levensol [et al.] (coord.) - Encompassing the Globe. Portugal e o Mundo nos séculos XVI e XVII. Lisboa: Museu Nacional de Arte Antiga, p. 60-61.

Garcia J C (2007) World map, known as the 'Cantino Planisphere', Portugal, ca. 1502; World map, Pero Fernandes (?) (active 1528-ca. 1545); Map of Brazil, from the Miller Atlas, Portugal, ca. 1519. In J A Levenson, et al. (coord.) Encompassing the Globe. Portugal and the World in the 16th and 17th centuries. Reference Catalogue, Washington, D.C.: The Arthur M. Sackler Gallery, Smithsonian Institution, Washington, D.C., II: 14-15; 16-17; 88-89.

Garcia J C, Almeida A F (2008) Il Deserto e le Rive del Mar: analisi di un portolano del Cinquecento / The Desert and the Coastlines: analysis of a Sixteenth Century Atlantic Chart. In Gullo G, Anselmo A (coord.) Il Portolano dell'Ammiraglio Corsaro: una carta nautical portughese del XVI secolo ritrovata nella Biblioteca Centrale della Regione Siciliana. Biblioteca Centrale della Regione Siciliana 'Alberto Bombace', Palermo: 23-33 e 53-56.

Lois C, Garcia J C (2009) Do oceano dos clássicos aos mares dos impérios: transformações car- tográficas do Atlântico Sul, Anais do Museu Paulista, XVII(2): 15-37. Disponível em: ttp://www.scielo.br/scielo.php?script=sci arttext\&pid=S0101-47142009000200003\&ln $\mathrm{g}=\mathrm{pt} \& \mathrm{nrm}=\mathrm{iso} \& \mathrm{tlng}=\mathrm{pt}$

Moreira M E S A, Dias M H (2005) Environmental dynamics of the Sado estuary mouth (Portugal): the old cartographic representations and the modern processes. In Sanjaume E, Mateu J F (coord.) Geomorfologia Litoral i Quaternari: homenatge al Professor Vicenç M. Rosselló $i$ Verger. Publicacions Universitat de València, València: 273-282. Disponível em: http://www.fl.ul.pt/mapoteca/Sado.pdf

Oliveira F R (2007) Verdadeira e perfeita Geografia de toda esta ribeira Indiana. Acerca das representações da Ásia marítima na cartografia dos descobrimentos/ A true and perfect Geography of the whole of his Indian coastline. On representations of maritime Asia in the Cartography of the Discoveries Era. Oriente, 18: 62-65.

\section{Cartógrafos e Instituições Cartográficas}

Almeida A F (2003) Samuel Fritz and the Mapping of the Amazon. Imago Mundi, 55: 113-119.

Almeida A F (2003) Samuel Fritz revisited: the Maps of the Amazon and their Circulation in Europe., Accademia Toscana di Scienze e Lettere 'La Colombaria', studi CCXIII: 133-153.

Dias M H (2007) Charles Bonnet: 1816-1967 [Em linha]; Pedro Teixeira: ca. 1595-1662 [Em linha]. In Crato N (coord.) Ciência em Portugal: personagens e episódios. Instituto Camões, Lisboa. Disponível em: http://www. instituto-camoes.pt/cve/ciencia/p67.html. [Acedido a 8 de Janeiro de 2011]; http://www. instituto-camoes.pt/cve/ciencia/p69.html. [Acedido a 9 de Janeiro de 2011].

Dias M H (2006) José Maria das Neves Costa, 17741841 [Em linha]; Francisco António Ciera, 1763-1814 [Em linha]; Bernardino Barros Gomes: 1839-1910 [Em linha]. In Crato N (coord.) Ciência em Portugal: personagens e episódios. Instituto Camões, Lisboa. Disponível em: http://www.instituto-camoes.pt/cve/ ciencia/p66.html. [Consult. 11 de Janeiro de 2011]; http://www.instituto-camoes.pt/cve/ ciencia/p48.html. [Consult. 11 de Janeiro de 2011]; http://www.instituto-camoes.pt/cvc/ 
ciencia/p59.html. [Acedido a 11 de Janeiro de 2011].

Dias M H (2001) Recordando um engenheiro português ao serviço da Cartografia militar. Boletim do Instituto Geográfico do Exército, 63: 37-51. Disponível em: http://www.igeoe.pt/

Dias M H (2000) A Cartografia militar portuguesa no final do milénio: rupturas e continuidades. Revista Militar, 52(4): 297-323.

Garcia J C (2010) Santarém 'le navigateur' à Paris. Cartes, diplomatie et sociétés savantes. In Besse, Jean-Marc ; Blais, Helène ; Surun, Isabelle (coord.) - Naissances de la Géographie Moderne (1760-1860). Lyon: École Normale Supérieure de Lyon, p. 57-82.

Garcia J C (2007) Realidades y desvarios: Armando Cortesão y la Historia de la Cartografía Portuguesa. In Jarauta F (coord.) El mundo de los mapas. Fundación Marcelino Botín, Santander: 199-214.

Garcia J C (2006) Manoel de Azevedo Fortes e os mapas da Academia Real da História Portuguesa, 1720-1736. In Fernandes M G (coord.) Manoel de Azevedo Fortes (1660-1749). Cartografia, Cultura e Urbanismo. Gabinete de Estudos de Desenvolvimento e Ordenamento do Território (GEDES) e Departamento de Geografia da Faculdade de Letras da Universidade do Porto, Porto: 141-173.

Oliveira F R, Garcia JM (2008). O Livro de Francisco Rodrigues - O Primeiro Atlas do Mundo Moderno (...).. Anais de História de AlémMar. IX, Lisboa: Universidade Nova de Lisboa: 440-447.

\section{Contributos Teóricos e Metodológicos}

Alegria M F (2003) Ainda o mundo era uma criança. In Campar A, et al. (coord.) Olhar o Mundo, ler o território: uma viagem pelos mapas. Instituto de Estudos Geográficos, Coimbra: 63-67.

Alegria M F (2001) A produção cartográfica portuguesa sobre o Brasil (1502-1655). Tentativa de tipologia espacial e temática. Sextas Jornadas de História Ibero-Americana, Portugal e Brasil no Advento do Mundo Moderno. Colibri, Lisboa: 59-89.

Almeida A F (2001) Entre a guerra e a diplomacia: os conflitos luso-espanhóis e a cartografia da América do Sul (1680-1777). A Nova Lusitânia: Imagens Cartográficas do Brasil nas colecções da Biblioteca Nacional (17001822). Comissão Nacional para as Comemorações dos Descobrimentos Portugueses, Lisboa: 37-65.

Baigent E, Gaspar J A, Moreira L M (2010) From the Portolan Chart of the Mediterranean to the plane chart of the atlantic: cartometric analysis and modelling. Maps of Portugal in the Eighteenth Century: From National Perspectives to Foreign Contributions, Imago Mundi, London: Routledge, 62: 1, 119-122.

Dias M H (2006) Cartografia [Em linha]. In Crato N (coord.) Ciência em Portugal: personagens e episódios. Instituto Camões, Lisboa. [Acedido a 3 de Janeiro de 2011]. Disponível em: http://www.instituto-camoes.pt/cve/ciencia/ d85.html. [Consult. 6 de Janeiro de 2011]; No dicionário incluem-se ainda as seguintes definições: mapa ou carta (http://www.institutocamoes.pt/cvc/ciencia/d94.html), mapa topográfico ou carta topográfica (http://www. instituto-camoes.pt/cvc/ciencia/d96.html), mapa temático ou carta temática (http://www. instituto-camoes.pt/cvc/ciencia/d95.html), carta hidrográfica e carta náutica (http://www. instituto-camoes.pt/cvc/ciencia/d84.html)

Dias M H (2006) - E se os utilizadores da informação geográfica se revoltassem?: algumas reflexões de desafio à Cartografia portuguesa. Fórum Geográfico. Lisboa: Instituto Geográfico Português. $\mathrm{N}^{\mathrm{o}}$ 1, p. 6-15. Disponível em: http://www.igeo.pt/servicos/CDI/biblioteca / PublicacoesIGP/imagens/forumgeografico OUT2006.pdf

Dias M H (2003) Grandes e pequenos passos da Cartografia portuguesa. In Campar A et al. (coord.) Olhar o Mundo, ler o território: uma viagem pelos mapas. Instituto de Estudos Geográficos, Coimbra: 59-63. Disponível em: http://www.fl.ul.pt/mapoteca/olhar_mundo_ mhdias.pdf

Dias M H (2002) Disponibilizar, utilizar e valorizar a informação cartográfica histórica: o projecto SIDCarta [CD-Rom]. ESIG 2002, VII Encontro de Utilizadores de Informação Geográfica (U.S.I.G.): comunicações. U.S.I.G. Lisboa.

Disponível em: http://www.igeo.pt/servicos/CDI/biblioteca/PublicacoesIGP/esig_2002/papers/ p031.pdf

Dias M H, Cauvin C, Alegria M F (2000) Comparação de configurações cartográficas através da regressão bidimensional. Finisterra - Revista 
Portuguesa de Geografia, XXXV(69): 95107. Dias M H, Soares F J, Fernandes S C, Amorim F (2005) Project SIDCarta: an information system for the History of Military Portuguese Cartography [CD-ROM]. GIS Planet 2005, II International Conference \& Exhibition on Geographic Information: proceedings. [s.1., s.n.].

Garcia J C (2005) Um castelo de cartas antigas: construir e comemorar o Império. In Coelho T P (coord.) Os Descobrimentos Portugueses no Mundo de Lingua Inglesa (1880-1972). Edições Colibri, Lisboa: 167-187.

Garcia J C (2004) Nos contrafortes dos Andes: reflexões geográficas sobre a Cartografia do Brasil setecentista. Mercator, III(6): 19-24.

Garcia J C (2003) Os desenhos do Capitão: nota sobre os percursos da informação nos mapas antigos. In Campar A, et al. (coord.) Olhar o Mundo, ler o território: uma viagem pelos mapas. Instituto de Estudos Geográficos, Coimbra: 69-70.

Garcia J C (2003) Some geographical notes on the practice of identifying maps. In Curto D R, Cattaneo A, Almeida A F (coord.) La Cartografia Europea tra primo Rinascimento e fine dell'Illuminismo. Atti del Convegno Internazionale 'The Making of European Cartography'. Leo S. Olschki Editore (Accademia Toscana di Scienze e Lettere 'La Colombaria', studi CCXIII), Florença: 325-330.

Garcia J C, Foldgomb A, Rákóczi I (2007) Kémek Vagy Atyák ? Szentmártonyi Ignác S.J. és a Brazil Térképészet [Padres ou espiões? Ignác Szentmártonyi S.I. e a Cartografia do Brasil] Budapeste: XXV(7): 84-87.

Garcia J C, Nogueira M (2001) Os sermões da restauração (1640-1668): um exercício cartográfico. Estudos em Homenagem a João Francisco Marques, I: 475-487.

Oliveira F R (2007) Viagem ao trono do mundo Inquérito sobre as fontes escritas e cartográficas da pretensa peregrinação de Fernão Mendes Pinto através da China em 1542-1544. Estudos sobre a China IX-Actas do $1^{\circ}$ Fórum Internacional de Sinologia. Centro de Estudos Chineses do Instituto Superior de Ciências Sociais e Políticas, Universidade Técnica de Lisboa, Lisboa: 225-264.

Oliveira F R (2010) História da cartografia brasileira e mapoteconomia segundo Jaime Cortesão: o curso do Itamaraty de 1944. [Em linha] $3^{\circ}$
Simpósio Iberoamericano de História da Cartografia: Agendas para História da Cartografia Iberoamericana, São Paulo 28 p. Disponível em: http://3siahc.files.wordpress. com/2010/04/francisco-roque-3siahc-2010. pdf

Oliveira F R (2010) Terra australis recenter inventa: o ressurgimento do mito da quarta parte do mundo na cartografia renascentista. [Em linha] Portugueses na Austrália. Coimbra: Museu da Ciência da Universidade de Coimbra, 29 p. Disponível em: http://www. museudaciencia.com/gfx/bd/100323152814 roque_oliveira2.pdf

Oliveira F R (2008). A cartografia e o conhecimento do território nos países ibero-americanos, Investigaciones Geográficas. Boletín del Instituto de Geografía de la Universidad Nacional Autónoma de México, 66: 167-171. Disponível em: http://www.igeograf.unam.mx/ instituto/publicaciones/boletin/bol66/bltn66resenas.pdf

\section{Colecções de Mapas e Atlas}

Almeida A F (2001) Mapa Geográfico de América Meridional, Juan de la Cruz Cano y Olmedilla, 1775; Plan de las Misiones Jesuitas y del paso por tierra de California con sus confinantes y de nuevas naciones en la America Septentrional, Juan José Díez (?), ca. 1760. AA.VV. - Tesoros de la cartografia española. Exposicion con motivo del XIX Congreso Internacional de Historia de la Cartografia. Catalogo. Biblioteca Nacional; Caja Duero, Madrid: 181-183; 197-199.

Almeida A F (2003) Introduzione; Cartografia e imperi; Carta Nautica dell'Atlantico, con parte delle Americhe, dell'Africa e dell'Europa, Luís Teixeira, ca. 1590; Imperii Sinarum Nova Descriptio, Martino Martini, 1655; Novissima et accuratissima totius Americae descriptio, 1655; Paraquariae Provinciae Societatis Iesu cum adiacentibus novissima descriptio, Antonio Machoni, 1760; Carte de la Province et des missions de la Compagnie de Jesus du Nouveau Royaume de Grenade, José Gumilla, 1758; Cours du Fleuve Maragnon autrement dit des Amazones, Samuel Fritz, 1717; Le Paraguay oú les RR. PP. de la Compagnie de Jésus ont répandu leurs missions, Jean Baptiste Bourguignon d'Anville, 
1733; Passage par terre à Californie, Eusebio Francisco Kino, 1705; Part of the Malabar Coast, Aaron Arrowsmith, 1822Accademia Toscana di Scienze e Lettere 'La Colombaria’, studi CCXIII:331-337; .350-358.

Almeida A F, Garcia J C (2007) Portugal en la Región Platina, siglos XVIII y XIX. Mapas de la Colección de la Dirección de Infraestruturas del Ejército (Lisboa, Portugal). Catalogo de la Exposición. In Portugal en la Región Platina. Homenaje a Luis Ferrand de Almei$d a$. Embajada de Portugal, Montevideo: 3794.

Almeida A F, Garcia J C (2000) A América Portuguesa nos Manuscritos da Biblioteca Pública Municipal do Porto. In A Terra de Vera Cruz. Viagens, Descrições e Mapas do século XVIII. Biblioteca Pública Municipal do Porto, Porto: 9-65.

Dias M H (coord.) (2007) Portugal em vésperas das Invasões Francesas: conhecimento geográfico e configurações: catálogo. Instituto Geográfico do Exército, Lisboa. Disponível em: http://www.igeoe.pt/downloads/expo_portugal_invasoes/Portugal_vesperas_Invasoes_ Francesas.pdf

Dias M H, Garcia J C, Almeida A F, Moreira L (coord.) (2005-2006) Cartografia militar portuguesa dos séculos XVIII e XIX: cartas, plantas, esboços e projectos. Comando da Zona Militar dos Açores e Presidência do Governo Regional dos Açores, Ponta Delgada e Angra do Heroísmo.

Garcia J C (2006) A História da Cartografia na obra do $2^{\circ}$ Visconde de Santarém. Exposição cartobibliográfica. Biblioteca Nacional, Lisboa.

Garcia J C (2006) Reunir, produzir e conservar: os mapas da Comissão de Cartografia. In Santos M E M, Lobato M (coord.) O domínio da distância: comunicação e cartografia. Instituto de Investigação Científica Tropical, Lisboa: 161-164.

Garcia J C (2006) Mapas e Atlas do Visconde de Santarém. A prioridade no descobrimento da África Ocidental. In Garcia J C (coord.) A História da Cartografia na obra do $2^{\circ}$ Visconde de Santarém. Exposição cartobibliográfica. Biblioteca Nacional, Lisboa: 7-16.

Garcia J C (2005) Plantas, Cartas, Esboços e Projectos. In Cartografia Militar Portuguesa dos séculos XVIII-XIX. Exposição. Viana do Castelo, Câmara Municipal de Viana do Castelo,
47 p. Garcia J C (2002) A mais dilatada vista do mundo. Inventário da colecção cartográfica da Casa da Ínsua. Comissão Nacional para as Comemorações dos Descobrimentos Portugueses, Lisboa.

Garcia J C (2001) A nova Lusitânia: imagens cartográficas do Brasil nas Colecções da Biblioteca Nacional. Comissão Nacional para as Comemorações dos Descobrimentos Portugueses, Lisboa.

Oliveira F R (2009) - Kunyu quantu 坤輿全圖 ("Complete Map of the World") drawn by Francesco Sambiasi, S.J., Nanjing (?), China, Ming Dinasty (ca. 1639). In Levenson J A, et al. (coord.) Encompassing The Globe - Portugal and the World in the 16th and 17th Centuries - 15 July-11 October 2009 [Exhibition catalogue]. Editorial coord. Ana de Castro Henriques. Museu Nacional de Arte Antiga, Lisboa: 63-64.

Oliveira F R (2007) - Sánchez Rubio, Rocío; Testón Núñez, Isabel; Sánchez Rubio, Carlos M. (eds.): Imágenes de un Imperio Perdido: el Atlas del Marqués de Heliche - Plantas de diferentes Plazas de España, Italia, Flandres y Las Indias [Ensaio bibliográfico]. Revista de História da Universidade de São Paulo, 156: 297-307. Disponível em: http://revhistoria.usp.br/images/stories/revistas/156/ RH_156_-_Francisco_Roque_de_Oliveira. pdf

Oliveira F R (2006) Imágenes de un Imperio Perdido: el Atlas del Marqués de Heliche. In Sánchez Rubio R, Testón Núñez I, Sánchez Rubio C M (eds.) Plantas de diferentes Plazas de España, Italia, Flandres y Las Índias. Anais de História de Além-Mar. Universidade Nova de Lisboa, Lisboa, 7: 412-419.

Ribeiro J M, Garcia J C (2010) Cabo Verde nos mapas manuscritos da Commissão de Cartographia. In Santos M E M S, Garcia J C (coord.) Álbum Cartográfico de Cabo Verde. Comissão de Cartografia (1883-1936). Instituto de Investigação e do Património Culturais, Cidade da Praia: 2-11.

Santos M E M S, Garcia J C (coord.) (2010) Álbum Cartográfico de Cabo Verde. Comissão de Cartografia (1883-1936). Instituto de Investigação e do Património Culturais, Cidade da Praia. 